\title{
The integral bridge design concept for the third runway at Heathrow, UK
}

Jessica Sandberg BE Hons (Civil Engineering), CEng, MICE Atkins Transportation, Epsom, UK (corresponding author: jessica.sandberg@atkinsglobal.com)

Luca Magnino BSc, MSc (Hons)

Atkins Transportation, Epsom, UK

Paul Nowak BSC (Hons), ARSM, CEng, CGeol, MICE, MIMMM, FGS

Atkins Infrastructure, Epsom, UK
Michael Wiechecki BEng (Hons), MIEAust

Atkins Infrastructure, Epsom, UK

Indrasenan Thusyanthan BA/MEng, PhD, FICE, CEng, CMarEng

Atkins Infrastructure, Epsom, UK

The Heathrow expansion project proposals comprise major works around Heathrow airport to allow the construction of new terminal buildings and the third runway. Owing to the critical nature of uninterrupted operation of both runway and the M25 motorway, the preliminary design had to be developed to minimise maintenance operations. At over $140 \mathrm{~m}$ in the total length, the adoption of an integral bridge of this length is in excess of most integral bridges in the UK, particularly where full-height abutments are being utilised. The maximum predicted expansion length also lies outside the limit equilibrium method set out in PD6694-1. As such, it was agreed that a full soilstructure interaction study should be carried out to assess the impacts of the structural behaviour of the bridge and its abutments. This paper looks at the calibration work for that study, the derivation of the earth pressures behind the walls, the behaviour of the abutment and how this compares with the predictions set out in PD 6694-1.

\section{Notation}

$C \quad$ factor allowing for stiffness of foundation material

$d_{\mathrm{d}} \quad$ design wall deflection at top of wall

$d_{\mathrm{d}}^{\prime} \quad$ wall deflection at a depth $H / 2$ below ground level when the end of the deck expands by distance $d_{\mathrm{d}}$

$E \quad$ elastic modulus

$E_{50} \quad$ secant stiffness of soil

$H \quad$ vertical distance from ground level to the level at which the abutment is assumed to rotate

$K_{\mathrm{a}} \quad$ coefficient of active earth pressure

$K_{\min } \quad$ coefficient of minimum earth pressure applied when earth pressure is favourable

$K_{\mathrm{p} ; \mathrm{t}} \quad$ coefficient of passive earth pressure used in the calculation of $K^{*}$ and determined using the design value of the triaxial $\phi^{\prime}$

$K^{*} \quad$ enhanced earth pressure caused by strain ratcheting

$K_{0} \quad$ at-rest earth pressure

$\alpha \quad$ coefficient of thermal expansion

$\gamma_{\mathrm{G}} \quad$ partial factor for permanent actions, also accounting for model uncertainties and dimensional variations

$\gamma_{\mathrm{Q}} \quad$ partial factor for variable actions, also accounting for model uncertainties and dimensional variations

$\gamma_{\text {soil drained soil weight }}$

$\phi^{\prime} \quad$ angle of shearing resistance in terms of effective stress

$\phi_{\mathrm{k}}^{\prime} \quad$ characteristic shear friction angle

$\psi \quad$ combination factor for variable action combination

\section{Background}

The Heathrow expansion project proposals comprise major works around Heathrow airport (London, UK) to allow the construction of a third runway and new terminal buildings. The third runway is proposed to run parallel to the M4 motorway and crosses the M25 motorway to the south of junction 15. To allow offline construction of the cut-and-cover crossing, the M25 will be realigned with provision for up to 20 lanes of traffic in its final condition as it is unlikely that future modifications to the structure will be feasible. The required width of the structure is approximately $140 \mathrm{~m}$ (transverse to the carriageway; see Figure 1) and the corridor affected by the runway, associated taxiways and access roads is approximately $700 \mathrm{~m}$ long. Abutment and pier heights vary between 9 and $17 \mathrm{~m}$ and will be overlain with up to $1.2 \mathrm{~m}$ of fill material to maximise distribution of the wheel loads from the aircraft while minimising the total weight on the structure.

Owing to the critical nature of uninterrupted operation to both Heathrow and Highways England assets at this location, the preliminary crossing design is to provide minimal maintenance throughout the design life. This led to an integral bridge as the preferred solution for the scheme, as it would remove the need for bearings and expansion joints. At just over $140 \mathrm{~m}$ deck length, this is well in excess of the recommendations in BD57/01 (HA, 2001), which requires designers to consider the use of integral bridges for deck lengths of less than $60 \mathrm{~m}$ and skew angles of less than $30^{\circ}$.

In the UK, integral bridge design is carried out in accordance with PD 6694-1 (BSI, 2011), where most bridges will be designed using the limit equilibrium (LE) method set out in clauses $9 \cdot 2 \cdot 1,9 \cdot 4 \cdot 3$ and $9 \cdot 4 \cdot 4$. However, the proposed structure marginally exceeds the LE maximum thermal expansion criteria of $40 \mathrm{~mm}$, where the structure had a maximum predicted 


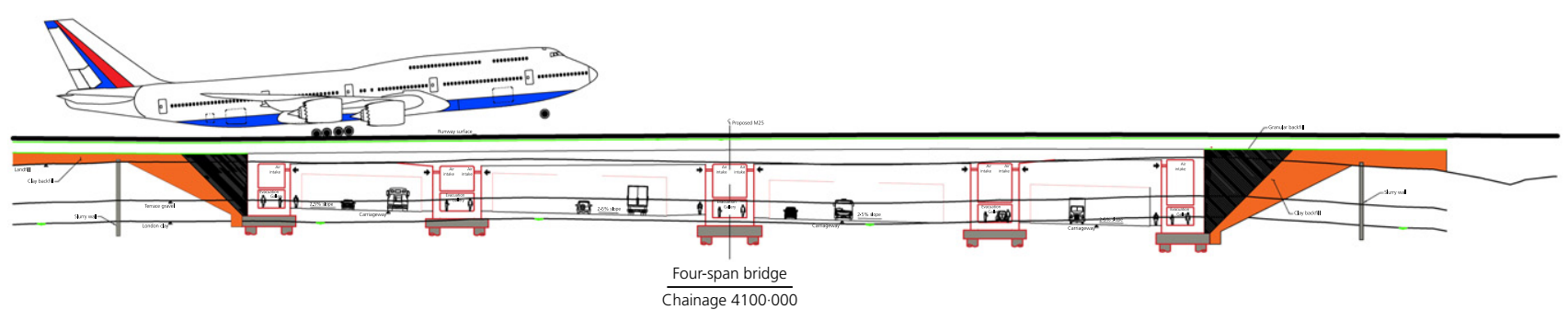

Figure 1. Typical transverse cross-section through the tunnel

movement range of $43 \mathrm{~mm}$. Furthermore, PD 6694-1 only provides guidance on the design of buried structures that are less than $15 \mathrm{~m}$ in deck length. Owing to this exceedance, combined with concerns from both Heathrow and Highways England regarding the future maintainability of the structure, it was considered necessary that a detailed soil-structure interaction (SSI), in accordance with PD 6694-1 clause $9 \cdot 2 \cdot 2$, be adopted for design development.

The purpose of the study was to confirm that an integral structure was suitable in this location. A structure width of $15 \mathrm{~m}$ was considered a sufficient representative width, where this section was based on the loading applied at the runway. As the fill depth had not yet been confirmed, a varying fill depth was considered, the main impact being the varying temperature range under consideration.

This analysis was split into several parts comprising

(a) derivation of the abutment design based on the LE method for comparison purposes

(b) development of the soil model to satisfy the requirements in clause $9 \cdot 2 \cdot 2$ of PD $6694-1$

(c) derivation of the earth resistance profiles based on the appropriate soil model to develop a realistic abutment design.

\section{LE approach}

Prior to conducting the SSI study, the abutment designs were developed using the LE design approach. Although the LE thermal expansion criterion was marginally exceeded at the ends of the structure, it was deemed that this would still provide a reasonable baseline for comparison purposes. The following assumptions were made to derive $K^{*}$ using the LE approach.

(a) A characteristic shear friction angle of $\phi_{\mathrm{k}}^{\prime}=42^{\circ}$ was considered as an upper bound limit for integral abutment backfill.

(b) The coefficient of lateral earth pressure 'at rest' $K_{0}=0.6$ was considered to account for locked-in stress during fill placement. (c) A drained soil weight $\gamma_{\text {soil }}=22 \mathrm{kN} / \mathrm{m}^{3}$ was considered as an upper bound limit.

(d) A coefficient of thermal expansion $\alpha=10 \times 10^{-6}{ }^{\circ} \mathrm{C}^{-1}$ was used as per the recommendations of BS EN 1992-1-1 (BSI, 2004) for concrete.

(e) An ultimate limit state (ULS) combination factor $\gamma_{\mathrm{G}}=1.35$ was used for dead, superimposed and earth loading, while $\gamma_{\mathrm{Q}}=1.55$ was used for thermal loading as per the National Annex to EN 1990 (BSI, 2005).

( $f$ ) Since combinations where thermal loading is not the leading variable action are unlikely to govern the abutment design, frequent combination factors (i.e. $\psi=0 \cdot 5-0 \cdot 6$ ) are ignored for this feasibility design stage.

(g) $\quad d_{\mathrm{d}}^{\prime}=0 \cdot 7 d_{\mathrm{d}}$ as per rotationally flexible walls was considered as an upper bound solution, as modelling indicated a rotationally flexible foundation (clause $9 \cdot 4 \cdot 3$ of PD 6694-1).

(h) A $C$ factor allowing for the soil stiffness below foundation level of $C=66$ (clause $9 \cdot 4 \cdot 3$ of PD 6694-1). This allows for the confining effects from rock, rather than piled stiffness, but was deemed the most appropriate value on which to base the comparison $(E \geq 1000 \mathrm{MPa})$.

Application of this approach led to an abutment wall thickness in excess of $2 \mathrm{~m}$, with three layers of B32 reinforcement bars in the hogging region of the deck-abutment connection. This was considered undesirable and unlikely to be practically buildable. The full SSI study was then carried out to develop a more realistic behaviour of the structure.

\section{Preliminary design of the runway structure}

\subsection{Design approach}

The study was conducted using a combination of geotechnical numerical software, Plaxis 2D 2016 (Plaxis), and structural modelling software, Lusas Bridge v.15 (Lusas). Plaxis has been developed specifically for analysis of SSI; however, the software is limited for structural analysis. Lusas was, therefore, adopted for structural analysis of the deck and superstructure. The varying abutment heights were captured by considering the structure's portals; the southern portal contains the tallest 
wall section $(17 \mathrm{~m})$, whereas the northern portal contains the shortest wall section $(9 \mathrm{~m})$.

The initial assumptions to be used for the SSI allowed for a design life of 120 years. This meant that 120 maximum expansion-contraction cycles were considered in the development of the soil resistance model, which is consistent with the approach set out in PD 6694-1. Although this is a conservative approach, no further calibration work was carried out to quantify the behaviour under varying temperature cycles to reflect actual conditions.

\subsection{Design for thermal effects}

Thermal effects were calculated as per BS EN 1991-1-5 (BSI, 2003) and modified in accordance with the UK National Annex. Fill depths up to $1.2 \mathrm{~m}$ are proposed to cover the structure and insulate it from the direct effects of aircraft wheel loading, whose point loads are likely to be significant. The study investigated the sensitivity of the structure to a range of temperature movements by considering temperature reduction effects in accordance with clause NA.2 $2 \cdot 2$ of the National Annex to BS EN 1991-1-5 where appropriate. The maximum thermal expansion ranges calculated for the $17 \mathrm{~m}$ and $9 \mathrm{~m}$ abutments are as follows.

- $17 \mathrm{~m}$ abutment (tallest wall section): $43 \mathrm{~mm}$ total movement comprising $23 \mathrm{~mm}$ contraction and $20 \mathrm{~mm}$ expansion (from vertical)

- $9 \mathrm{~m}$ abutment (shortest wall section): $24 \mathrm{~mm}$ total movement comprising $13 \mathrm{~mm}$ contraction and $11 \mathrm{~mm}$ expansion (from vertical).

\subsection{Developing the SSI soil model}

Plaxis has several constitutive models available to simulate the behaviour of soils, of which, the hardening soil (HS) soil model has been shown to be the most suitable Plaxis model to capture the soil behaviour behind integral bridge abutments by several published works (Efretuei, 2013; Kerokoski, 2006; Naggar and Mahgoub, 2016). However, PD 6694-1 clause 9.2.2 states: 'Where numerical modelling is carried out, it is important that the approach used has been calibrated against comparable experience, laboratory modelling and/or case history data experience to demonstrate compatibility in deflection and soil stress profile down the depth of the abutment after 120 thermal cycles.'

To satisfy PD $6694-1$ clause $9 \cdot 2 \cdot 2$, the HS model was verified by simulating the laboratory testing by England et al. (2000). England et al.'s work formed part of a research programme commissioned by the Highways Agency (now Highways England) in the late 1990s to examine the fundamental mechanisms responsible for the build-up of lateral earth resistance behind integral abutments. The laboratory testing comprised a series of seven 1:12 scale model retaining wall experiments to

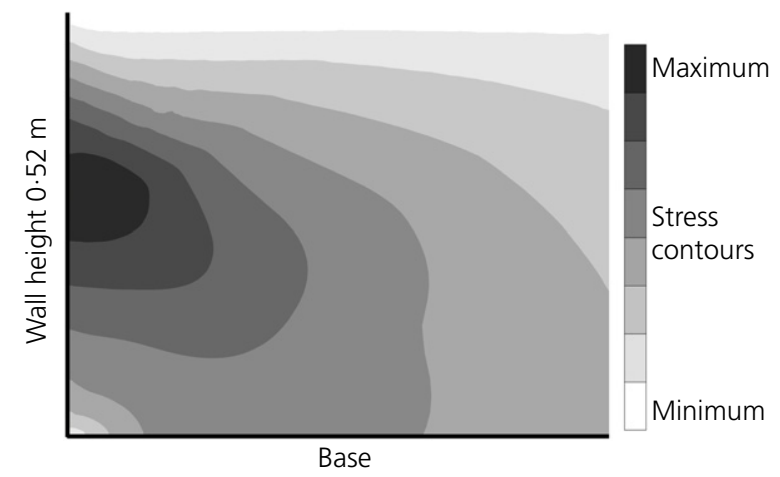

(a)

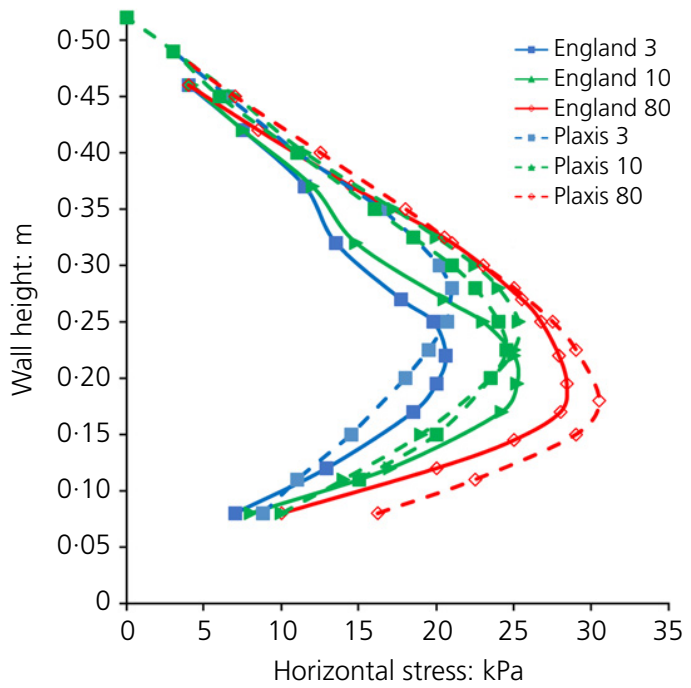

(b)

Figure 2. Plaxis model results: (a) lateral stress contours after first cycle; (b) comparison between Plaxis model results and England et al. (2000) SW25 laboratory results

simulate seasonal movements of a stiff wall, in concrete bridges with deck lengths of 60, 120 and $160 \mathrm{~m}$. The findings from the studies were incorporated into BA 42/96 Amendment 1 (HA, 2003) (from BA 42/96 1996), and later into the current PD 6694-1, which has been adopted as a design guide by Highways England for integral bridges.

The results of the England et al. (2000) simulation using Plaxis are presented in Figures 2 and 3. Numerical back-analysis was able to capture the increase in wall pressure over 120 thermal cycles as observed by England et al. Similar stress profiles are achieved after three, ten and 80 cycles, and the Plaxis wall reaction ratio (denoted $K$, with the maximum value reached equivalent to $K^{*}$ ) correlates well with England et al.'s measured result.

The primary increase in $K$ is observed in the first 40 cycles, with $K$ increasing marginally (tailing off) over the remaining 
cycles to a ' $K^{*}$ ' of about $3 \cdot 9$. In comparison, the England et al. scaled test achieved ' $K$ ' ' of about 4 .

It is acknowledged that England et al.'s experiment adopted Leighton Buzzard sand, which is markedly different to integral abutment backfill, which typically comprises gravelly

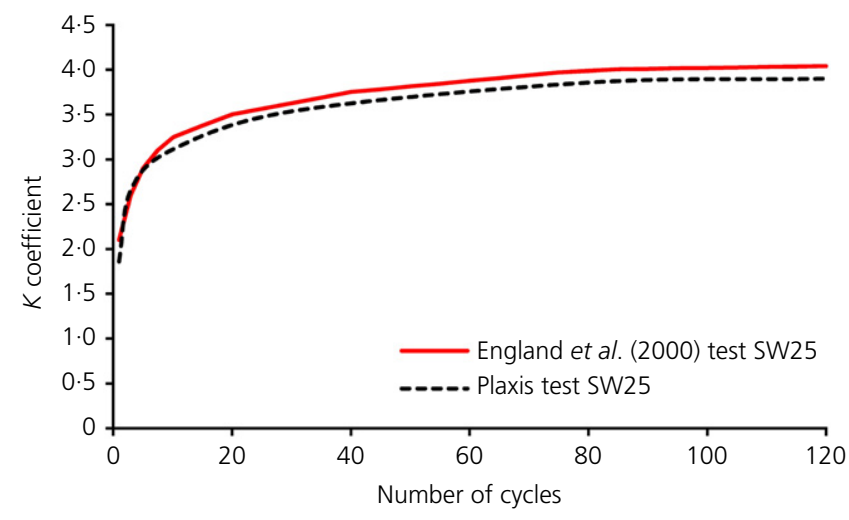

Figure 3. Development of $K^{*}$; comparison between England et al. (2000) and Plaxis model

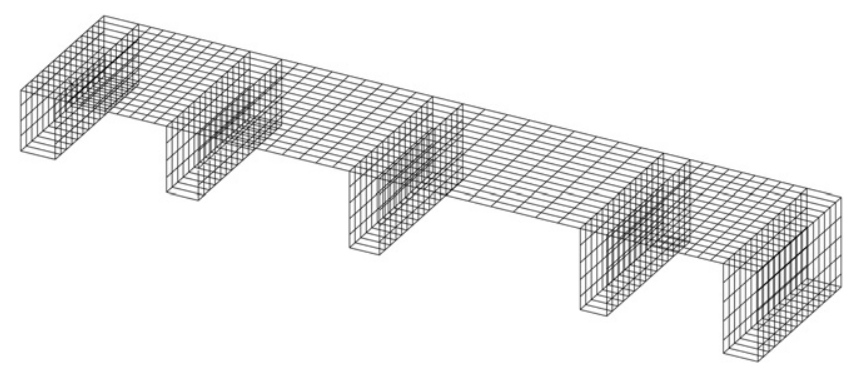

Figure 4. Three-dimensional grillage representing northern portal portion of the tunnel
Class $6 \mathrm{~N} / 6 \mathrm{P}$ as outlined in series 600 of the Specification of Highway Works (MCHW, 2016). The simulation work presented has not altered the constitutive model provided in Plaxis, but rather has demonstrated the HS model's ability to capture 'strain ratcheting' effects. The HS model was therefore considered suitable for use on the M25 feasibility study to evaluate earth resistance during thermal deck movements.

Detailed insights associated with the soil modelling will be published in a future paper.

\subsection{Developing the SSI structural model}

The superstructure was modelled in Lusas as a spaceframe, with each portal approximately $30 \mathrm{~m}$ wide (along the length of the M25), see Figures 4 and 5. The deck was modelled as $2 \mathrm{~m}$ deep hollow concrete slab, while the pier and abutment walls were modelled as rectangular concrete sections, with $1 \mathrm{~m}$ and $2 \mathrm{~m}$ thickness, respectively. The expansion movement was derived based on the model behaviour from the structural analysis.

The pile group behaviour was simulated using equivalent cantilevers, whereby the foundation stiffness of the pile group was modelled using a cantilever with an appropriate stiffness. The equivalent cantilevers are derived based on the flexibility matrix, and then displacements and rotations at the pile cap are matched. This approach is discussed in more detail in Sandberg et al. (2018). The flexibility matrix was then refined to obtain consistency between the Lusas and Plaxis models for a nominal load case. Additional prescribed displacements were required at both head and fixity point of the equivalent cantilever elements to simulate construction-induced movements that are inherently captured in the Plaxis model; placement of fill behind the abutment causes lateral movement of the pile cap.

Earth pressure/resistance resulting from deck contraction/ expansion, either assessed following the LE approach or from the SSI analysis, were applied in Lusas as patch loads acting

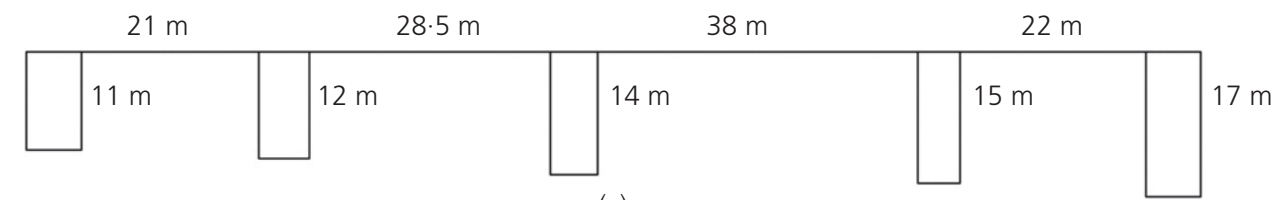

(a)

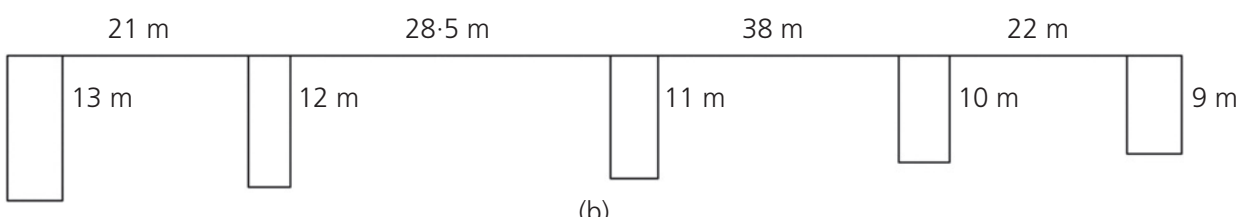

Figure 5. (a) Southern and (b) northern portal model cross-sections 


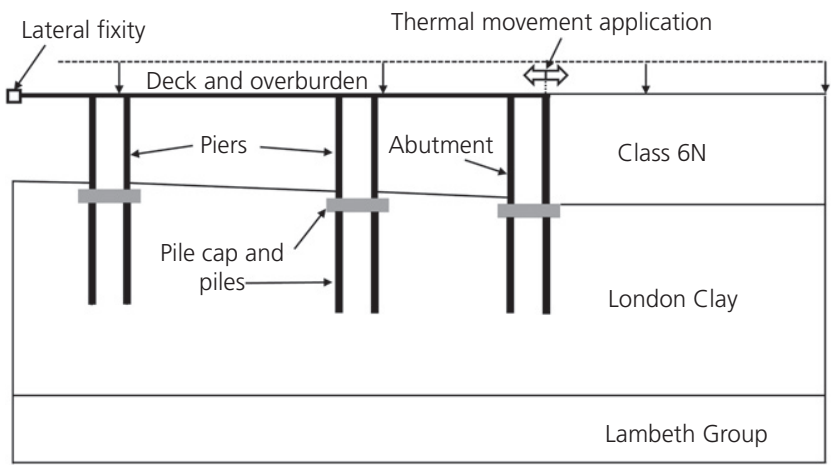

Figure 6. Plaxis model used for SSI analysis

on the abutment walls. The overburden above the deck was applied as a line load at the top of the abutment wall element.

An equivalent Plaxis 2D structural model was developed for each Lusas model, as shown in Figure 6. The deck, pier and wall elements were modelled using plate elements, and assigned structural properties as per the Lusas model (based on a metre-wide strip). Piles were modelled as embedded beam elements, and the pile cap was modelled using a volume element to provide adequate connection to the superstructure. The fill above the structure was modelled as an equivalent surcharge, and a bottom-up construction sequence was considered. Thermal deck movements, extracted from Lusas, were applied as a prescribed lateral point displacement at the top of the abutment. Lateral fixity was applied to the deck, at the point of zero expansion (determined from the Lusas model). This ensured correct structural behaviour of the internal piers.

\section{Model calibration and abutment design}

\subsection{Backfill soil parameters}

The Plaxis HS model was updated to reflect the proposed Class 6N/6P backfill, as assumed for the LE approach. However, the LE approach does not consider soil stiffness which is an essential parameter in SSI analysis. PD 6694-1, clause A.3.2 suggests two methods for determining soil stiffness, as follows.

(a) Derive directly from drained triaxial testing.

(b) Derive from published data on small-strain stiffness.

PD 6694-1 provides a method for calculating stiffness based on the work by Seed and Idriss (1970); however, it should be noted that this method relates to sands as opposed to gravels. Correlations for small-strain values of gravel are said to be much less reliable (O’Brien, 2013).

No laboratory testing was conducted as part of the preliminary design works. Therefore, a range of secant stiffness $\left(E_{50}\right)$ between 100 and $200 \mathrm{MPa}$ was considered for the Class $6 \mathrm{~N} / 6 \mathrm{P}$

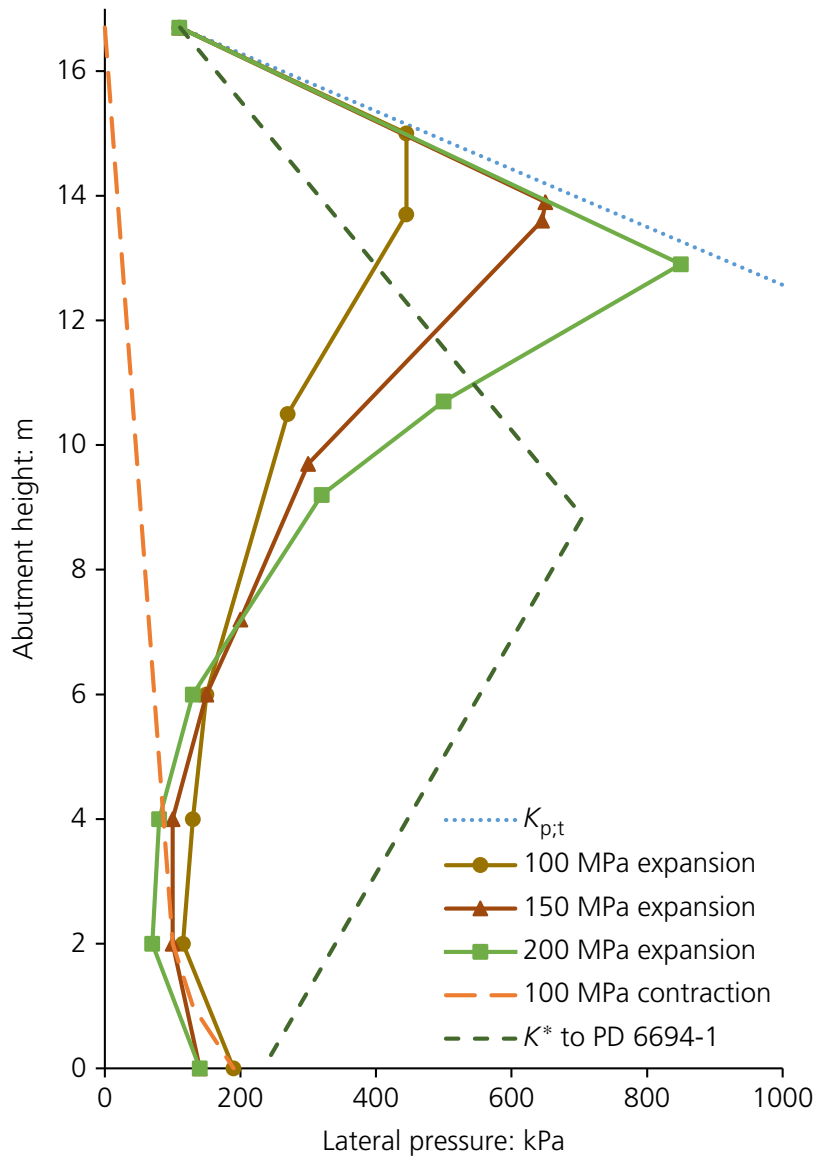

Figure 7. Lateral earth resistance variation dependent on soil stiffness (defined as a pressure)

based on the published literature (Efretuei, 2013; Honkanadavar and Sharma, 2016; Maqbool and Koseki, 2007; Tatsuoka et al., 2013).

A parametric study was conducted to assess the development of mobilised earth resistance due to this range of soil stiffness when subject to the maximum thermal expansion range. To minimise computation time, the number of cycles was limited to ten, which was sufficient to identify the sharp increase in $K$ observed during the HS verification process (Figure 3 ). The resulting earth resistance profiles (including that from the LE approach) for the $17 \mathrm{~m}$ abutment are presented in Figure 7. It can be observed there are several clear differences between the SSI earth resistance profile and the LE $K^{*}$ profile.

- The SSI stress profile at the top of the wall follows the passive limit $\left(K_{\mathrm{p} ; \mathrm{t}}\right)$ rather than the typical $K^{*}$ slope proposed in the LE approach.

- The SSI peak mobilised earth resistance is proportional to soil stiffness magnitude (for a given thermal displacement), and can exceed LE $K^{*}$ peak resistance magnitude. 
Bridge Engineering

Volume 173 Issue 2
The integral bridge design concept for

the third runway at Heathrow, UK

Sandberg, Magnino, Nowak, Wiechecki and

Thusyanthan

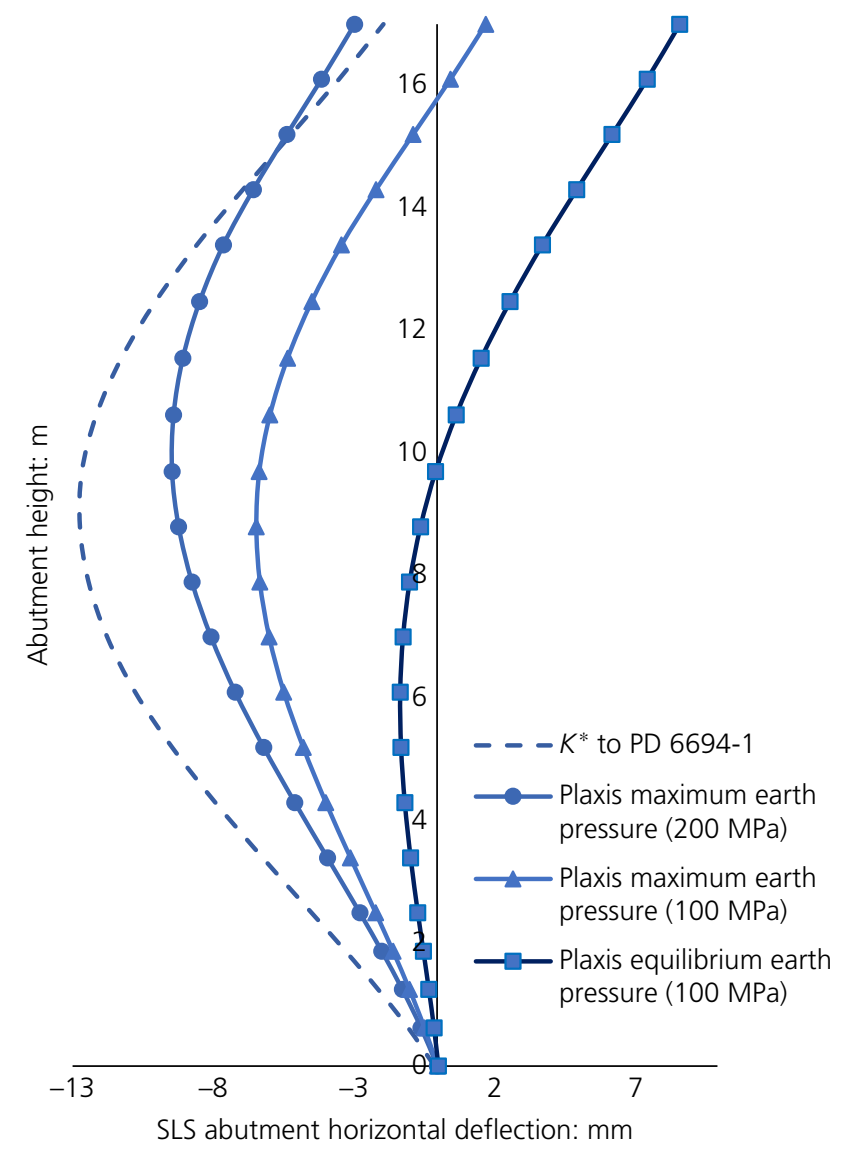

Figure 8. Lusas abutment deflected shape variation depending on the soil stiffness; negative movement indicates contraction and positive movement indicates expansion (from vertical) (SLS, serviceability limit state)

- Below the peak resistance, the SSI approach develops significantly less lateral stress in comparison to the LE approach. This can be attributed to abutment flexibility, which is not considered in the LE approach.

The earth resistance distributions in Figure 7 were analysed in the Lusas model and the associated abutment deflection profiles are presented in Figure 8. The corresponding abutment displacement for the $150 \mathrm{MPa}$ and $200 \mathrm{MPa}$ stiffness profiles, and the LE $K^{*}$ profile, causes a net contraction of the structure which is not consistent with the physical phenomenon; net contraction would develop active earth pressures that are considerably lower than the passive earth resistance. Therefore, to progress design, a backfill secant stiffness of $100 \mathrm{MPa}$ was adopted.

\subsection{Structural behaviour}

Although the $100 \mathrm{MPa}$ stiffness profile caused net expansion, the displacement at the top of abutment from the Lusas model $(+8 \mathrm{~mm})$ is less than that applied in the Plaxis model
$(+20 \mathrm{~mm})$. This suggests the actual magnitude of thermal expansion is also proportional to backfill resistance and, hence, soil stiffness. Note that the current LE method ignores this relative stiffness, whereby movement of the structure is based on the unrestrained deck movement.

To establish the equivalent earth resistance for an associated thermal displacement, an iterative analysis methodology was developed between Lusas and Plaxis to achieve consistent abutment displacement profiles as follows.

(a) Calculate the maximum design value of deck movement $d_{\mathrm{d}}$ in Lusas, ignoring the presence of backfill.

(b) Apply $d_{\mathrm{d}}$ in Plaxis for 120 thermal cycles. Extract lateral earth resistance profile.

(c) Apply resistance profile as patch loading in Lusas and combine with the maximum design temperature case.

(d) Compare displacement profiles of the abutment between Lusas and Plaxis. If consistent, software equilibrium is achieved. Otherwise compute an averaged deflection $d_{\mathrm{d}}$ at the top of the abutment and repeat steps $(b)$ to $(d)$.

(e) Complete the structural analysis. Reductions to member sizes may warrant repeating steps $(b)$ to $(e)$ for further structural optimisation.

To streamline the approach and reduce the model variables, the iterative approach initially considered fixity/rigid conditions below the pile cap level (including beneath the abutment backfill). Once equilibrium was achieved, fixity was removed, and the process was repeated to include the SSI of the piles and surrounding strata.

Figures 9 and 10 present the lateral earth resistance profiles obtained for both the fixed and non-fixed cases compared against those obtained by the LE predictions for the $17 \mathrm{~m}$ and $9 \mathrm{~m}$ high abutments, respectively. The associated net wall resistance is summarised in Tables 1 and 2.

It is evident that the SSI fixed foundation case mobilises more earth resistance than the SSI non-fixed case. This trend is consistent with the basis behind the foundation stiffness factor $(C)$ in the LE approach, whereby confining effects cause stress accumulation.

However, as identified during the stiffness parametric study, there are clear differences between the earth resistance profiles calculated using SSI and that obtained using the LE approach. The SSI earth resistance profile follows the passive limit $\left(K_{\mathrm{p} ; \mathrm{t}}\right)$ rather than the typical $K^{*}$ gradient. The peak resistance is shown to develop much higher in the abutment stem (as opposed to the abutment midpoint), which focuses most of the increased resistance in the region immediately behind the deck. 


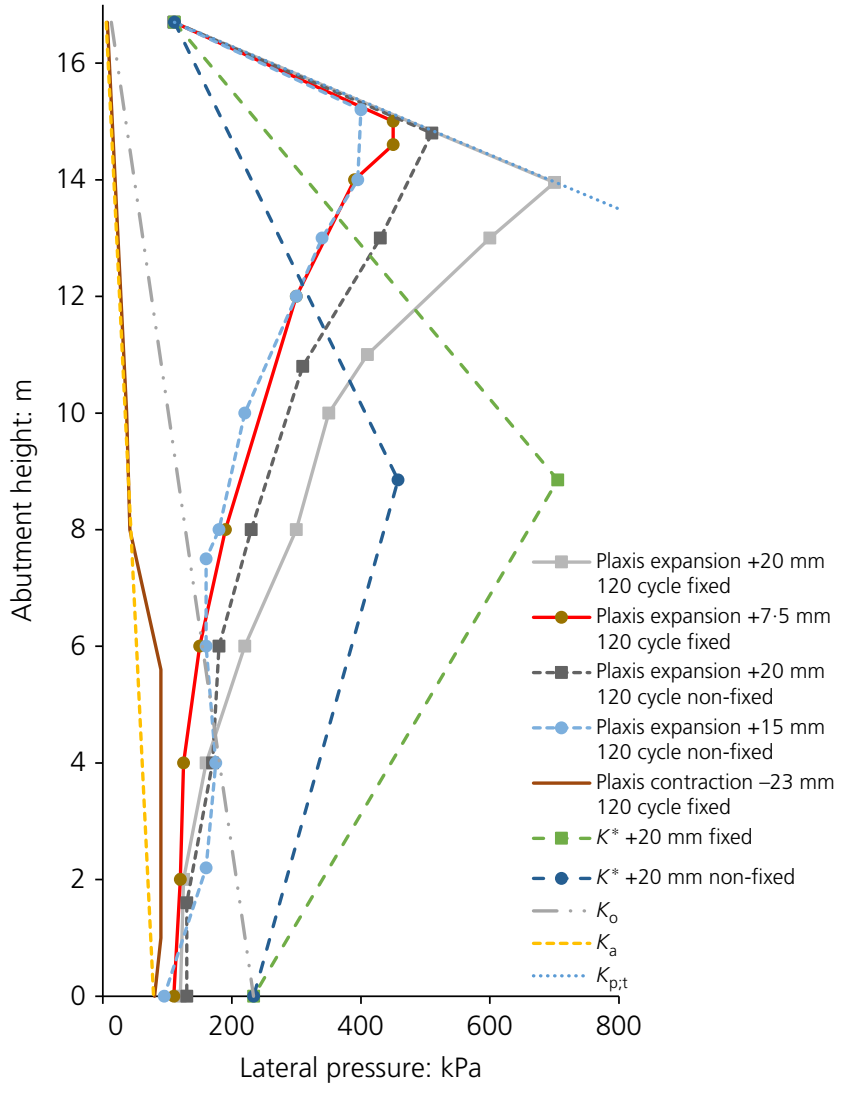

Figure 9. Earth resistance variation on $17 \mathrm{~m}$ high wall shown as a pressure

Also, although the SSI peak resistance value exceeds the LE prediction, significantly less earth resistance is developed below the peak. At the base of the abutment, the stress profile reduces towards the 'at rest' pressure of $K_{0}$ as per the LE approach.

For the $17 \mathrm{~m}$ high wall, the net lateral stress calculated using SSI was more than $50 \%$ less than that calculated using the LE approach. The $9 \mathrm{~m}$ abutment wall was found to behave more rigidly, with a $35 \%$ decrease in net resistance, compared to the LE approach. This is likely to be due to the assumption of a $2 \mathrm{~m}$ wall thickness, and a second internal wall at close proximity, which is unusually stiff compared to most integral bridges. It is therefore likely that further iteration to refine the design will lead to greater reduction in earth resistance.

The effect on abutment design between the SSI and LE approach is presented in Figures 11 and 12, which show the associated bending moment profile for the $17 \mathrm{~m}$ and $9 \mathrm{~m}$ wall, respectively, overlain on section capacities for $1 \mathrm{~m}, 1.5 \mathrm{~m}$ and $2 \mathrm{~m}$ walls. It is evident that there is significant economic benefit in adopting the SSI analysis for the $17 \mathrm{~m}$ high wall. The SSI approach yields a wall thickness of between $1 \mathrm{~m}$ and

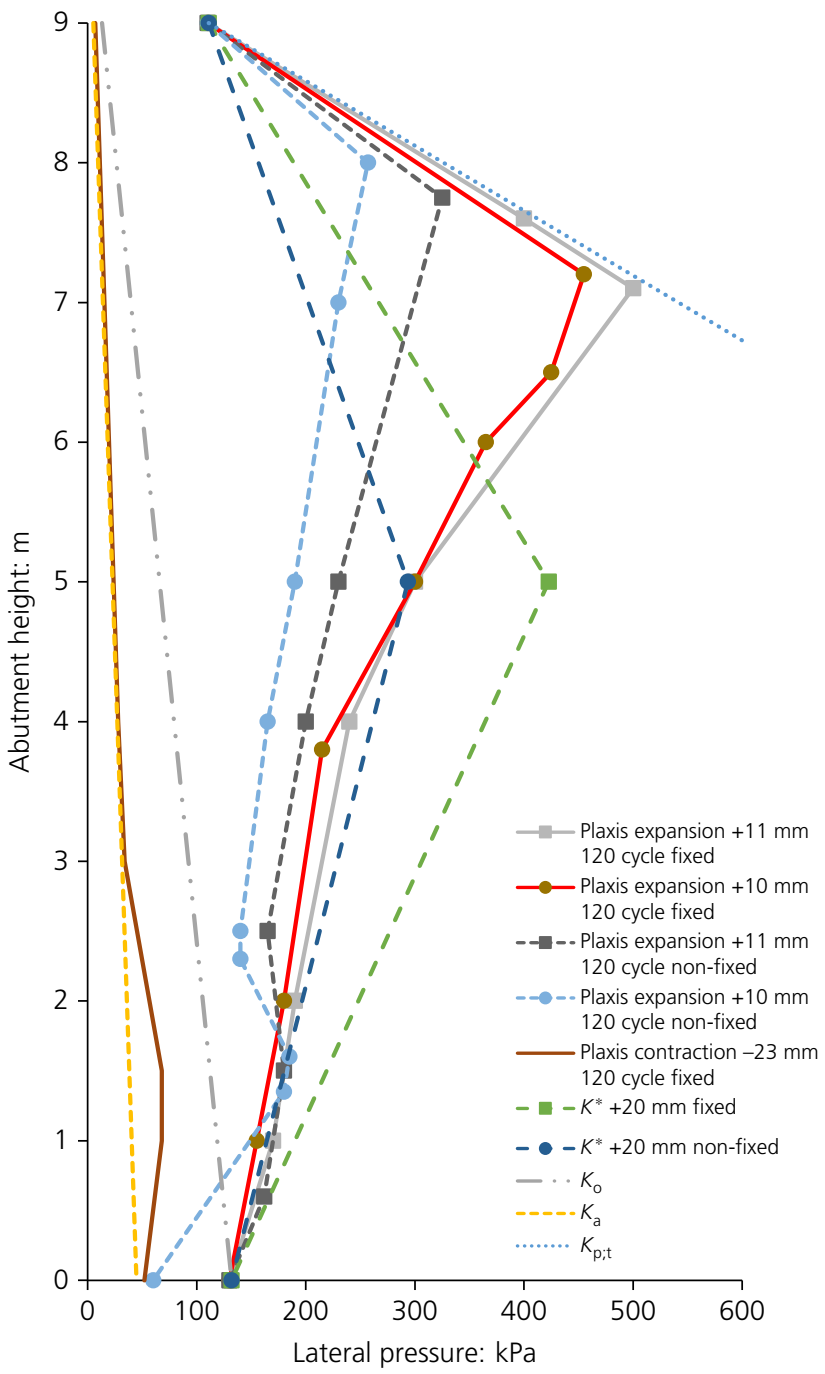

Figure 10. Earth resistance variation on $9 \mathrm{~m}$ high wall, shown as earth pressures

$1.5 \mathrm{~m}$, whereas the LE approach requires a wall thickness well in excess of $2 \mathrm{~m}$. While less benefit was observed in the design of the $9 \mathrm{~m}$ wall, as noted above, it is likely that reducing the stiffness of the wall in the models to $1 \cdot 0 \mathrm{~m} / 1 \cdot 2 \mathrm{~m}$ will lead to further reductions in the predicted moments due to the additional flexibility of the structure.

The temperature contraction case was also investigated, although there is little guidance within PD 6694-1 currently. The implication is that $K_{\min }\left(K_{\mathrm{a}}\right)$ pressures should be used in deriving the earth pressure for the contraction case. The SSI study indicated that, as the deck contracts and pulls the wall away from the soil, the lateral earth pressure obtained initially follows the theoretical active profile $K_{\mathrm{a}}$ and then increases towards $K_{0}$ towards the abutment. 
Table 1. Resistance acting on abutment due to earth pressure on $17 \mathrm{~m}$ wall

\begin{tabular}{lllcc} 
Foundation & Method & Profile & Net resistance: $\mathbf{k N} / \mathbf{m}$ & Reduction: \% \\
\hline- & LE & LE $K^{*}-23 \mathrm{~mm} /+23 \mathrm{~mm}$ & 7360 & N/A \\
Fixed & SSI & Equilibrium $-23 \mathrm{~mm} /+7 \cdot 5 \mathrm{~mm}$ & 3680 & 50 \\
Non-fixed & SSI & Equilibrium $-23 \mathrm{~mm} /+15 \mathrm{~mm}$ & 3310 & 55
\end{tabular}

Table 2. Resistance acting on abutment due to earth pressure on $9 \mathrm{~m}$ wall

\begin{tabular}{lllcr} 
Foundation & Method & Profile & Net resistance: kN/m & Reduction: \% \\
\hline- & LE & LE $K^{*}-23 \mathrm{~mm} /+11 \mathrm{~mm}$ & 2450 & N/A \\
Fixed & SSI & Equilibrium $-23 \mathrm{~mm} /+10 \mathrm{~mm}$ & 2330 & 5 \\
Non-fixed & SSI & Equilibrium $-23 \mathrm{~mm} /+10 \mathrm{~mm}$ & 1590 & 35
\end{tabular}

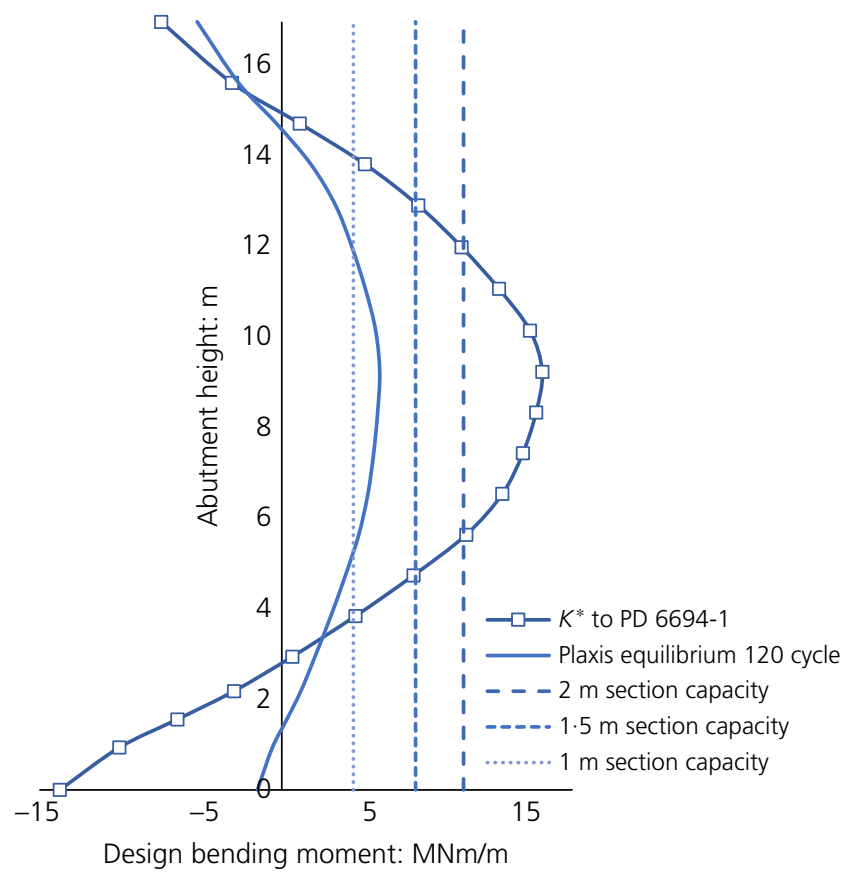

Figure 11. Predicted design bending moment along the height of the $17 \mathrm{~m}$ high abutment

\section{Conclusions and further work}

This paper presents a comprehensive SSI study to understand the behaviour of a $140 \mathrm{~m}$ long integral bridge during thermal deck movements. It demonstrates the sensitivity of an integral structure to the stiffness of both the structure itself and the surrounding soil. These parameters are not currently included within the commonly adopted PD 6694-1 LE design approach.

The predicted earth resistance values calculated using the SSI approach were compared with those based on the PD 6694-1 LE approach, and it was found that there were significant

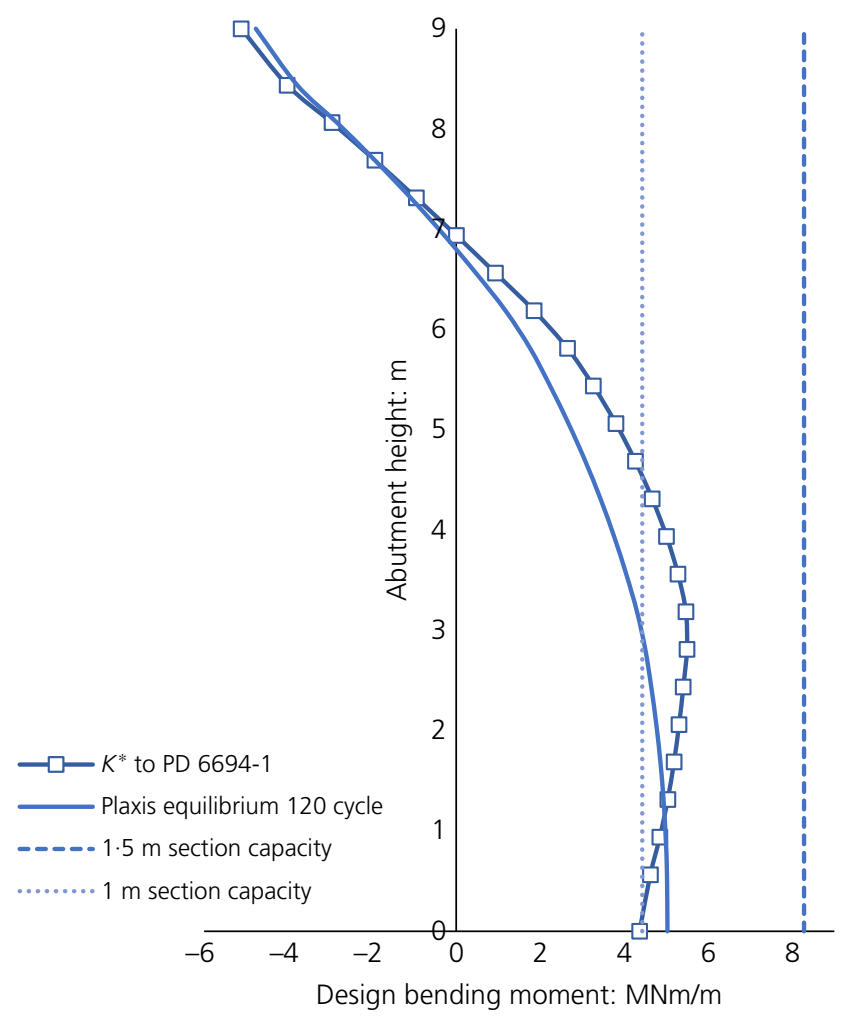

Figure 12. Predicted design bending moment along the height of the $9 \mathrm{~m}$ high abutment

discrepancies in stress profiles. In contrast to the LE approach, the earth resistance profile at the top of the wall follows the passive limit, $K_{\mathrm{p} ; \mathrm{t}}$, rather than the typical $K^{*}$ gradient. Furthermore, the peak resistance was found to develop much higher in the abutment stem instead of the abutment midpoint, focusing most of the increased resistance in the region immediately behind the deck. Below the peak value, the SSI approach developed significantly less earth resistance, leading 
to $35-50 \%$ overall reduction in net lateral stress. This directly benefits the structural design by reducing section sizes and reinforcement requirements. The LE approach would have otherwise deemed the structure undesirable and unlikely to be practically buildable.

Based on the above study, further work should be carried out on a range of abutment heights and stiffnesses to establish the effects of stiffness of both structure and soil. Investigating a range of abutments would also provide an indication of whether or not the current LE design rules in PD 6694-1 provide an accurate representation of loading behind abutment walls.

\section{Acknowledgements}

Published with the kind permission of Highways England and Heathrow airport.

\section{REFERENCES}

BSI (2003) BS EN 1991-1-5: Eurocode 1: Actions on structure general actions- thermal actions. BSI, London, UK.

BSI (2004) BS EN 1992-1-1: Eurocode 2: Design of concrete structures. BSI, London, UK.

BSI (2005) NA to BS EN 1990: UK national annex for Eurocode basis of structural design. BSI, London, UK.

BSI (2011) PD 6694-1: Recommendations for the design of structures subject to traffic loading to BS EN 1997-1:2004, BSI, London, UK.

Efretuei E (2013) Thermal Impact on Soil-Structure Interaction for Integral Bridges. University of Leeds, Leeds, UK.

England GL, Tsang CM and Bush D (2000) Integral Bridges - A Fundamental Approach to the Time Temperature Loading Problem. Thomas Telford Publishing, London, UK.

HA (Highways Agency) (2001) Design Manual for Roads and Bridges, Vol. 1, Section 3, Part 3. BD 57/01: Design for Durability. Highways Agency, London, UK.
HA (2003) Design Manual for Roads and Bridges, Vol. 1, Section 3, Part 12. BA42/96: Amendment No. 1, The Design of Integral Bridges. Highways Agency, London, UK.

Honkanadavar N and Sharma K (2016) Modelling the triaxial behaviour of riverbed and blasted quarried rockfill materials using hardening soil model. Journal of Rock Mechanics and Geotechnical Engineering 8: 380-365

Kerokoski O (2006) Soil-Structure Interaction of Long Jointless Bridges with Integral Abutments. Tampere University of Technology, Tampere, Finland.

Maqbool S and Koseki J (2007) Large-scale plane strain compression tests on compacted gravel. Pakistan Journal of Engineering and Applied Sciences 1(1): 40-60.

MCHW (Manual of Contract Documents for Highway Works) (2016) Specification for Highway Works: Series 600 - Earthworks. Highways Agency, London, UK, vol. 1.

Naggar H and Mahgoub A (2016) Impact of the employed soil model on the predicted behaviour of integral abutment bridges. Proceedings of the 69th Canadian Geotechnical Conference, Vancouver, Canada. Canadian Geotechnical Society, Surrey, BC, Canada.

O'Brien A (2013) Foundation types and conceptual design principles. In ICE Manual of Geotechnical Engineering. Volume II Geotechnical Design, Construction and Verification (Burland J, Chapman T, Skinner H and Brown M (eds)), 2nd edn. ICE Publishing, London, UK, p. 757.

Sandberg J, Argyle T, Petty R, Patel B and Nowak P (2018) The design of integral bridges with bankseat, half height and full-height abutments. Proceeding of the Institution of Civil Engineers Bridge Engineering 171(3): 222-234, https://doi.org/10.1680/ jbren.17.00018.

Seed H and Idriss I (1970) Soil Modulus and Damping Factors for Dynamic Response Analyses. Earthquake Engineering Research Center, University of California, Berkley, CA, USA, Report EERC 70-10.

Tatsuoka F, Tomita Y, Iguchi Y and Hirakawa D (2013) Strength and stiffness of compacted crushed concrete aggregate. The Japanese Geotechnical Society, Soils and Foundations 53(6): 835-852

\section{How can you contribute?}

To discuss this paper, please email up to 500 words to the editor at journals@ice.org.uk. Your contribution will be forwarded to the author(s) for a reply and, if considered appropriate by the editorial board, it will be published as discussion in a future issue of the journal.

Proceedings journals rely entirely on contributions from the civil engineering profession (and allied disciplines). Information about how to submit your paper online is available at www.icevirtuallibrary.com/page/authors, where you will also find detailed author guidelines. 